\title{
A DUMBBELL URACHAL CYST
}

\author{
Senthilvel Arumugam1, Saravanan Kanakasabapathy², Rajesh Kannaiyan ${ }^{3}$ \\ ${ }_{1}^{1}$ Senior Assistant Professor, Department of Urology, Govt. Royapettah Hospital, Chennai. \\ ${ }^{2} \mathrm{HOD}$, Department of Urology, Govt. Royapettah Hospital, Chennai. \\ ${ }^{3}$ Resident, Department of Urology, Govt. Royapettah Hospital, Chennai.
}

\section{ABSTRACT}

The urachus is an embryological tubular structure extending from the umbilicus to the urinary bladder apex, which usually gets obliterated but may persist uncommonly in adults. Rarely, the urachus may be the primary site of benign and malignant neoplasms. Urachal malignancies are rare and represents less than $1 \%$ of all bladder neoplasms.

\section{CASE REPORT}

A 39-year-old female presented with pain and lump in the lower abdomen for 6 months' duration. No other symptoms. History of caesarean section 8 years back. On examination, a lower midline scar present. A vague swelling of size $6 \times 5 \mathrm{~cm}$ present in the left lower abdomen adjacent to scar, surface smooth, firm, non-tender and non-reducible. Provisional diagnosed as irreducible, nonobstructing incisional hernia. Routine investigations were normal. Ultrasonogram abdomen was equivocal. CT abdomen plain and oral contrast confirmed a urachal cyst with subcutaneous component, so we planned for diagnostic laparoscopy and exploration. Intra-operatively, a $4 \times 4 \mathrm{~cm}$ midline cystic mass infra-umbilical, well away from bladder dome. Abdominal component was mobilized laparoscopically using monopolar hook. A connecting component was identified entering the linea alba close to umbilicus into subcutaneous plane. Further laparoscopic dissection abandoned. A small mid-midline incision was made and both components excised in-toto. The final histopathology report came as fibrocollagenous, fibromyxoid, fibrofatty cyst wall lined by cuboidal to polygonal epithelial cells with focal atypia. Features consistent with urachal cystadenoma with focal atypia.

\section{CONCLUSION}

Rarely described in literature, it should be treated as mucinous cystadenoma of undetermined malignant potential which has the tendency for local recurrence should be completely excised. Followup of these tumours is mandatory, as it presents with focal atypia.

\section{KEYWORDS}

Urachus, Remnant, Cystadenoma, Benign.

HOW TO CITE THIS ARTICLE: Arumugam S, Kanakasabapathy S, Kannaiyan R. A dumbbell urachal cyst. J. Evolution Med. Dent. Sci. 2016;5(50):3236-3238, DOI: 10.14260/jemds/2016/750

\section{INTRODUCTION}

The urachus is an embryological tubular structure extending from the umbilicus to the urinary bladder apex, which usually gets obliterated but may persist uncommonly in adults.[1] Rarely, the urachus may be the primary site of benign and malignant neoplasms. Urachal malignancies are rare and represents less than $1 \%$ of all bladder neoplasms.[2] Urachal mucinous neoplasms are still rare and include cystadenoma, cystadenocarcinoma. It has indolent course and variable mode of presentation. Here, we present a case report of 39 years old female patient who presented with pain and lower abdominal mass with history of caesarean section, where complete excision was done and the final histology revealed urachal cystadenoma with focal atypia. This has been rarely described in the English literature and should be treated by complete surgical excision to rule out malignancy. ${ }^{[3]}$

\section{CASE REPORT}

A 39-year-old female presented with complaints of pain and lump in the lower abdomen for the past 6 months' duration. No history of fever, vomiting. No history of abdominal distension.

Financial or Other, Competing Interest: None.

Submission 03-05-2016, Peer Review 01-06-2016,

Acceptance 07-06-2016, Published 23-06-2016.

Corresponding Author:

Dr. Senthilvel Arumugam,

Department of Urology,

Govt. Royapettah Hospital,

West Cott Road, Roypettah,

Chennai-600014.

E-mail: arusenthil2014@gmail.com

DOI: $10.14260 /$ jemds $/ 2016 / 750$
No history of bowel symptoms. No history of haematuria and other urinary symptoms. History of caesarean section 8 years back. Patient had no co-morbid conditions. On examination her general condition was good, examination of cardiovascular and respiratory systems was normal. Perabdomen, a lower midline scar was present. A vague swelling of size $6 \times 5 \mathrm{~cm}$ present in the left lower abdomen adjacent to lower midline scar, surface smooth, firm, non-tender and nonreducible. A provisional diagnosis of irreducible, nonobstructing incisional hernia was initially made out. Urine examination, urine culture were normal. Renal function tests were normal. Ultrasonogram abdomen showed features equivocal with cystic mass lesion or bowel herniation, possibility of incisional hernia and suggested contrast computed tomogram of abdomen. Hence, a plain and oral contrast computed tomogram of abdomen and pelvis taken, which showed a $4 \times 3 \mathrm{~cm}$ midline cystic lesion pre-peritoneal in its location above the bladder extending through linea alba into the subcutaneous plane on left side infra-umbilical. Features consistent with urachal cyst with a subcutaneous component (Fig. 1, 2). So we planned for diagnostic laparoscopy followed by exploration. Under general anaesthesia patient in supine position after bladder catheterization diagnostic laparoscopy was done. A 4x4 cm midline cystic mass infra-umbilical, well away from bladder dome (Fig. 3). Abdominal component was mobilized laparoscopically using monopolar hook. A connecting component was identified entering the linea alba close to umbilicus into subcutaneous plane. Further laparoscopic dissection abandoned. A small mid-midline incision was made, linea alba incised opened, peritoneal cavity entered, intra- 
abdominal component delivered. Further dissection proceeded to deliver the subcutaneous component without difficulty in-toto (Fig. 4). Haemostasis secured wherever necessary. Wound closed in layers. Specimen sent for histopathological examination. Post-operative periods were uneventful. No urinary complications. Sutures removed and patient discharged on $10^{\text {th }}$ postoperative day. The final histopathological report came as fibrocollagenous, fibromyxoid, fibrofatty cyst wall lined by cuboidal to polygonal epithelial cells with focal atypia. Features consistent with urachal cystadenoma with focal atypia.

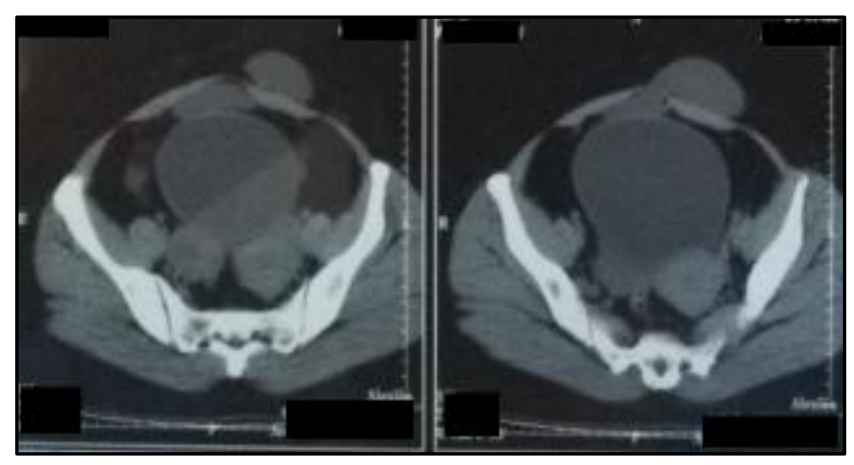

Fig. 1: CT Abdomen Plain showing the Cyst with Two Component

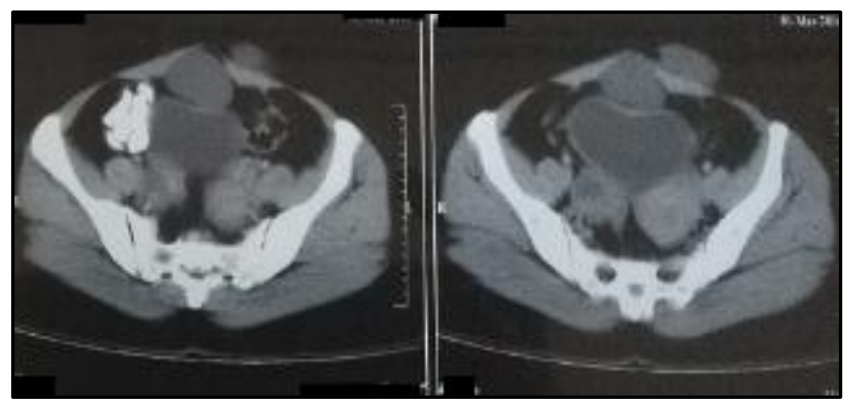

Fig. 2: CECT Abdomen showing Non-Enhancing Cyst Separated from Bladder and Bowel

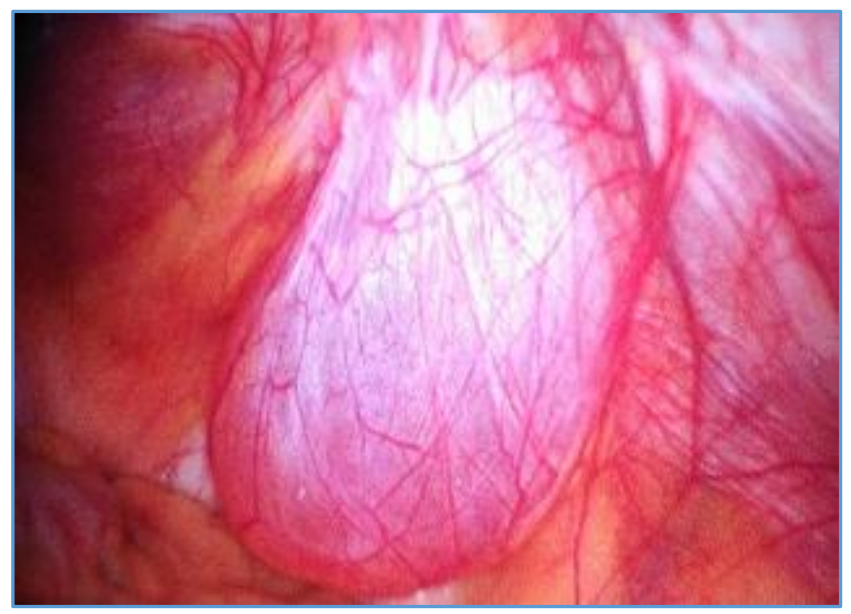

Fig. 3: Laparoscopic View Cyst

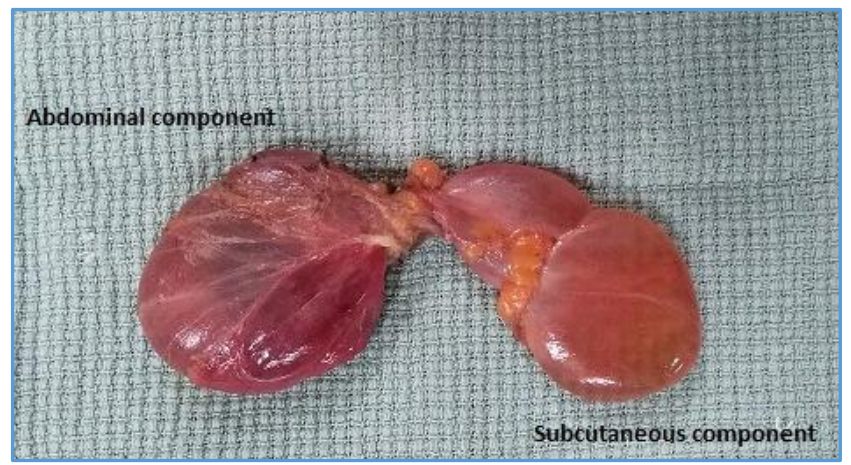

Fig. 4: Gross Specimen showing the Two Component

\section{DISCUSSION}

Urachus is a tubular structure that connects the urinary bladder to the allantois during embryonic development. It arises from the bladder apex within the pre-vesical space of Retzius and connects to the umbilicus. Urachus is an epithelium lined tubular structure surrounded by connective tissue, musculature but may lack musculature often. The epithelial lining may be columnar, cuboidal, goblet cells or transitional cells in varying proportions. Usually, it undergoes complete regression to form the median umbilical ligament, but incidentally seen in $30 \%$ of autopsies in adults. Urachus may persist in adults, depends upon the level of luminal closure it can lead to various anomalies. They are 1 . Patent urachus where the lumen is completely open, 2. Urachal cyst where there is no connection to bladder or umbilicus, which is commonest in its occurrence around $36 \%$, 3. Urachal sinus where only the umbilical end that is open, which may discharge secretions sometimes called as weeping umbilicus, 4. Vesicourachal diverticulum where only the bladder end that is open.[1] Tumours can occur from these remnants, which could be either benign, malignant or metastatic deposits from various primary sites that include breast, pancreas, ovary, prostate, intestine, etc. Benign neoplasms of urachus include desmoid tumour, leiomyoma, fibroma and villous adenoma. Urachal tumours usually remain undiscovered for a long period, because of their obscured location.

Either incidentally found or present at an advanced stage of disease, urachal mucinous cystadenocarcinoma is the predominant malignant tumour.[2] But there is a wide spectrum of its presentation; they are mucinous cystadenoma, mucinous cystic tumour of low malignant potential, mucinous cystic tumour of low malignant potential with intraepithelial carcinoma and microscopically or frankly invasive mucinous cystadenocarcinoma. ${ }^{[3,4]}$ The commonest of this is mucinous cystic tumour of low malignant potential around $60 \%$. The pathogenesis is not completely understood. The term mucinous tumour of uncertain malignant potential has been given for urachal mucinous tumour without frank invasion, but having tendency for local recurrence and development of pseudomyxoma peritonei. It is believed that urachal carcinomas arise from malignant transformation of columnar or glandular metaplastic epithelium. Our case presented as a dumbbell cystic tumour, which initially posed diagnostic difficulty with incisional hernia later confirmed with computed tomogram.

But here one question arises, what would be the cause for its subcutaneous presentation? This could be probably because the urachal remnants, which was in pre-peritoneal 
location before caesarean section might had entangled in the wound, hence in the pfannenstiel scar later and segregated to subcutaneous plane. From the history it is clear that the swelling developed over a period of time, which she noticed for past 6 months. What caused the development of the cyst is unclear, since it is longer duration after the caesarean section. Though we completely excised the cyst, the final histopathology report came as benign urachal cystadenoma with focal atypia; however, in view of focal atypia the patient is on regular followup.

\section{CONCLUSION}

Rarely described in literature, it should be treated as mucinous cystadenoma of undetermined malignant potential which has the tendency for local recurrence, should be completely excised. Followup of these tumour is mandatory, as it presents with focal atypia.

\section{REFERENCES}

1. Eble JN. Abnormalities of the urachus. In: Young RH, editor. Pathology of the urinary bladder. New York: Churchill Livingstone 1989:213-43.

2. Sheldon CA, Clayman RV, Gonzalez R, et al. Malignant urachal lesions. J Urol 1984;131(1):1-8.

3. Hull MT, Warfel KA. Urachal cystadenoma with abundant glycogen: ultrastructural study. Ultrastruct Pathol 1994;18(5):499-502.

4. Paner GP, Lopez-Beltran A, Sirohi D, et al. Updates in the pathologic diagnosis and classification of epithelial neoplasms of urachal origin. Advances In Anatomic Pathology 2016;23(2):71-83. 